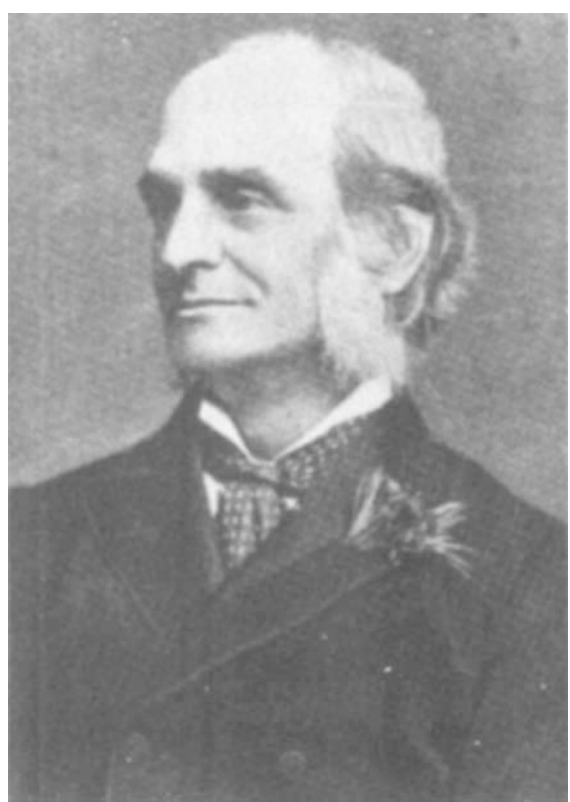

Ernest Hart - a "sense of self-importance" (reproduced from Mirror of Medicine)

years, such as malnutrition, poverty and unemployment. Perhaps the most notable achievement of his period was the redesign of the Journal's format, by Stanley Morison, with the appearance of the nowfamiliar logo, the work of Eric Gill.

Horner was in ill-health during the last years of his editorship, and his deputy, Hugh Clegg, was effectively the editor for several years before being officially appointed in 1947, just in time to greet the birth of the National Health Service. Clegg was not enamoured of either Aneurin Bevan or his plans for the NHS, but he was realistic enough to recognize that medical opposition could not stop their implementation, and as the Appointed Day (7 July 1948) came nearer, he used the Journal to urge doctors to cooperate, and survived an attempt by some irate BMA members to have him sacked for his pains. Clegg proved to be a strong editor, as difficult personally as Hart, but equally effective in restoring the Journal's flagging reputation.

Bartrip ends his account with Clegg's retirement in 1965, although the present editor, Stephen Lock, has written a thoughtful postcript on the philosophy that has guided the Journal's production during the past quarter of a century.

Considering their importance, it is surprising that scientific and medical periodicals have attracted so little scholarly attention. Bartrip's monograph thus sets a standard and, one might dare to hope, a precedent. I can think of a number of other periodicals whose histories would make illuminating reading, of which Nature comes pretty close to the top of the list.

W.F. Bynum is at the Wellcome Institute for the History of Medicine, 183 Euston Road, London NW1 2BN, UK.

\section{Hypocrisies and half-truths}

\author{
Roy Porter
}

Follies and Fallacies in Medicine. By Petr Skrabanek and James McCormick. Prometheus Books: 1990. Pp. 147. $\$ 19.95$.

THE recent inquiry, published in the Lancet, into the survival prospects of patients attending the Bristol Cancer Help Centre in the United Kingdom, elicited the most drearily predictable set of responses. Spokesman for orthodox oncology tended to say "we told you so - we always knew these quack treatments were worthless", while advocates of alternative medicine queried the statistics, or claimed their publication was "premature", because the result betrayed "hope". What is so refreshing, by contrast, about Skrabanek and McCormick's entertaining syllabus of medical errors is the independent gadfly spirit of the enterprise. Wielding the lancet of critical reason against nonsense, pomposity and illogic wherever they are found, the pair slaughter the sacred cows of all manners of medicine, regular and irregular, without fear or favour.

Alternative systems form, not surprisingly, the most vulnerable sitting targets, and the authors direct devastating shafts of wit against the more gullible sectors of the fringe. How can anyone truly believe that homeopathic medications work thanks to the extremes of dilution widely recommended (and mystifyingly dubbed 'potentization'), or that the essence of their efficacy lies in

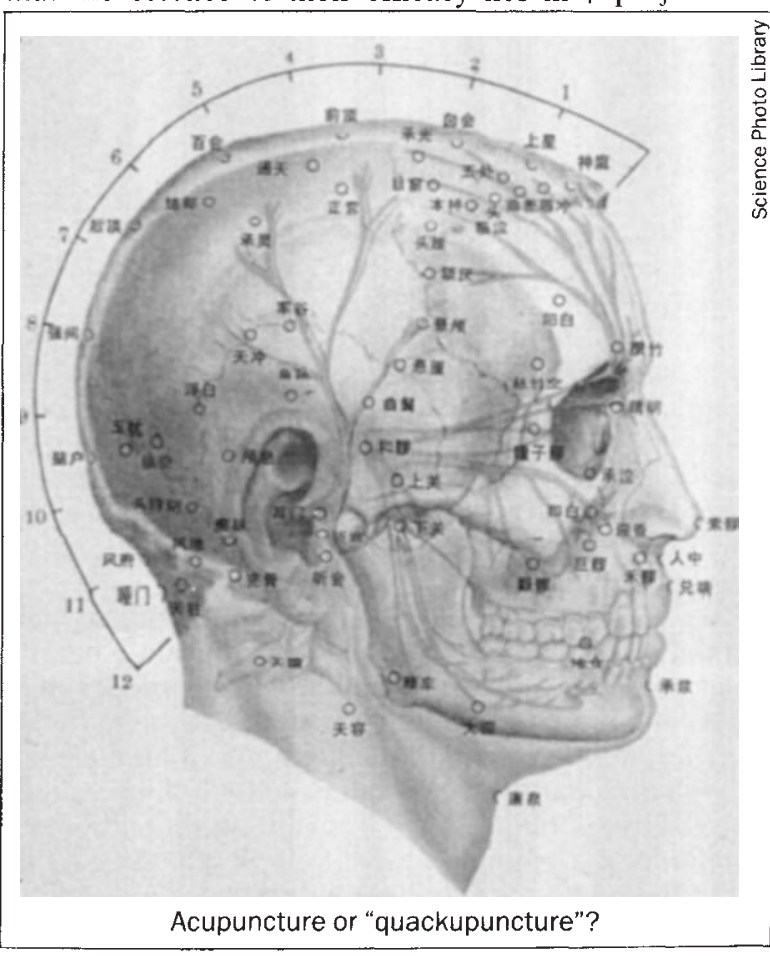

the way they are shaken? Skrabanek and McCormick in their dossier of delusions dismiss acupuncture as "quackupuncture"; adjudge Christian science to be neither Christian nor scientific; and expose psychic surgery as a pernicious fraud.

But, when it comes to credulity, is orthodox medicine's track record so very much better? An entertaining chapter entitled "A Fistful of Fallacies" offers an alphabet of the absurdities of establishment medicine: from false faith in therapeutics (A recovers after taking medicine $B$, therefore B cures A: the causal link is all too often simply assumed), to semantic obfuscation and a terminal addiction to polysyllabics. Drawing upon Bacon's critique of the "idols of the mind", and adding a generous pinch of H. L. Mencken's short way with prejudices, the authors lay bare the sloppy handling of statistics still pervading so many supposedly scientific clinical trials, and expose the way dubious diagnostic labels all too often serve as cloaks for ignorance and surrogates for understanding.

They are not critical of medicine per se, Skrabanek and McCormick insist, they merely want criticism in medicine. Nor is their stance wholly destructive. On the positive side, they argue that because medicine cannot be an exact science - it is, rather, a technique of healing - the human factor must be paramount.

Hence they have some robust recommendations about healing. All surveys confirm that the doctor can wield a magical power. Inert drugs, prescribed with the right flourish of confidence, produce a placebo effect; the bedside manner is itself therapeutically effective. Why, then prejudice aside - has so little attention been paid to the promotion of this kind of faith-healing within medicine? Isn't it time medical education capitalized upon the obvious healing power of the placebo?

'Prevention' forms another instance where specious theory may be taking precedence over the real interests of the patient. In the abstract, the extension of screening procedures (for example, for cervical cancer) may seem incontestible. But, taken in the round, do the outcomes actually bear this out? Include all the undesirable, and, too often, ignored, side-effects - false positives, surgical intrusions and the vast and mainly needless psychological anxiety created - and it is less clear where the balance of benefit lies.

Avoiding cynicism

or 
nihilism, Skrabanek and McCormick demand constant critical vigilance and radical scrutiny of the taken-for-granted. Are we not losing our sense of proportion if we assume the yard-stick of medical progress is the prolongation of life at all costs? May not quality of life, freedom from anxiety and individual liberty count for more? It is fashionable to scare people into health with campaigns against cholesterol and the promotion of regular checkups; but exposing people to half-baked diets and additional doctoring may be just as harmful.

Occasionally, Skrabanek and McCormick hoist themselves on their own petard, when their debunking passion evidently learned from Martin Gardner gets the better of their own critical faculties. They assert, sweepingly, that "the present activities of surgeons general, health education councils, and many

\section{Hominid whodunnit}

\section{G. Ainsworth Harrison}

Piltdown. A Scientific Forgery. By Frank Spencer. Oxford University Press: 1990. Pp. 272. £17.95, \$24.95.

The Piltdown Papers. By Frank Spencer. Oxford University Press: 1990. Pp. 282. £30, $\$ 65$.

THE fascination of the Piltdown forgery is apparently endless. It was indeed one of the most gigantic frauds in scientific history: it bedevilled understanding of the fossil record of human evolution and went unexposed for more than forty years. Perhaps the continuing fascination comes from the fact that the circumstances of the perpetration of the fraud remain obscure, and the guilty party or parties not unequivocally identified. Whether one can get nearer to the truth eighty years on than J. S. Weiner's exposure of the fraud in 1953 is rather doubtful, but nonetheless Spencer's book is a scholarly and important contribution to the now enormous literature dealing with the Piltdown forgery.

The nature of the original finds, which were apparently extracted from the lower Pleistocene gravels near Uckfield in Sussex, in the United Kingdom, between 1912 and 1915, are well known: the finds consisted of substantial parts of a human cranium which was essentially modern; much of a mandibular horizontal ramus which was very ape-like; a canine-tooth which fitted perfectly the prediction of Sir Arthur Smith Woodward; sufficient of a second individual to show that one was not dealing with a fortuitous association; and some artefacts and fossil mammals. All turned out to have been 'salted', and the academic departments of public health and the like, are in danger of corrupting medicine by morality". Maybe, but, by their own criteria, we're at least entitled to some evidence of this. All the reader gets, however, is an anecdote from Manila and a quotation from Plato: hardly proof positive of a point whose rhetoric is rousing but which actually requires serious evaluation.

Yet Follies and Fallacies never expects to be the last word. Fired especially at medical students, it aims to provoke more than to prove. And in this it succeeds, and leaves one looking forward to a further training of the Skrabanek and McCormick artillery against hypocrisies and halftruths.

Roy Porter is at the Wellcome Institute for the History of Medicine, 183 Euston Road, London NW1 2BN, UK.

jaw and teeth 'doctored' to show some human characters

Subsequent fossil discoveries, particularly in Africa, made Piltdown ever more anomalous. Human evolution proceeded by modification of the jaws before substantial change in the size of the brain, rather than the other way round. Nonetheless, authors of books on palaeoanthropology in the 1940s still gave a central place to Piltdown, often identifying it with the ancestry of modern man. In such schemes, other fossils were all side branches. That such a position could be sustained for so long is remarkable - at least with hindsight! It was not helped by the fact that almost everyone working on
Piltdown had to work with caste material. But eventually Weiner recognized what a nonsense it was, proposed the forgery explanation, demonstrated in collaboration with K.P. Oakley and Sir Wilfrid Le Gros Clark the scientific basis to the fraud and undertook his own investigation into the perpetrators. He concluded in his book The Piltdown Forgery (1955) that Charles Dawson, a local solicitor, amateur naturalist and the 'discoverer' of the first finds, almost certainly had to be heavily involved; but whether he was alone or had accomplices was not completely clear. On balance, Weiner favoured Dawson's sole involvement.

Since then many others have tried their detective skills, and fingers have been pointed at almost every possible figure associated with the finds or with Dawson. It seems that one only needed to have purchased potassium dichromate (which was used to 'fossilize' the bones) around 1912 to have come under suspicion. Strangely, perhaps, one of the few people to escape accusation has been Sir Arthur Keith, then conservator of the Hunterian Museum of the Royal College of Surgeons, who devoted much of his life to researching Piltdown, particularly the reconstruction of the cranium from the fragments recovered. That omission is corrected in Spencer's book, in which the proposition is developed that Keith was Dawson's scientific accomplice and perhaps instigator of the whole affair.

Keith's involvement was first seriously suggested by Ian Langham, a young Australian historian and anthropologist who died tragically in 1984. Langham's work

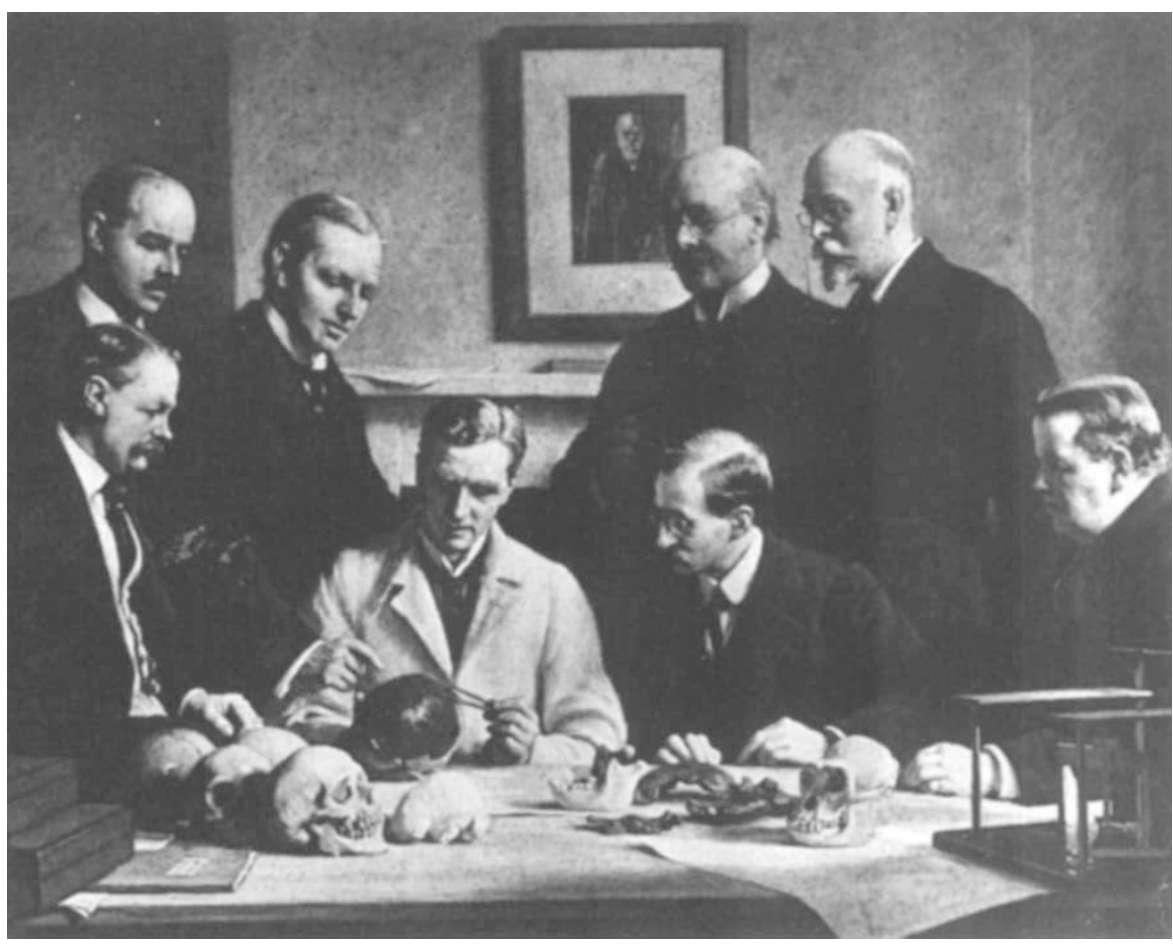

The 'Piltdown gang' as painted by John Cooke - Arthur Keith is seated (centre) wearing a labcoat, Charles Dawson and Arthur Smith Woodward are standing (left and right, respectively) to the right of the painting. 